\title{
Optimum Designing of Gas Distribution Networks of Ilam Province by Using GIS Network and Spatial Analysis
}

\author{
Hosein Anvari 1* ${ }^{*}$ Bakhtiar Feizizadeh ${ }^{2}$, Rasool Olyani Nejad ${ }^{1}$ \\ ${ }^{1}$ Area of Study Geographic Information Systems, Tabriz, Iran \\ ${ }^{2}$ Faculty Member of Tabriz University, Tabriz, Iran \\ Email: Anvari@gmail.com
}

Received 4 July 2016; accepted 15 August 2016; published 18 August 2016

Copyright (C) 2016 by authors and Scientific Research Publishing Inc.

This work is licensed under the Creative Commons Attribution International License (CC BY). http://creativecommons.org/licenses/by/4.0/

(c) (†) Open Access

\begin{abstract}
Undoubtedly, pipeline transport is considered as significant economical artery of country and national valuable resources, so it is necessary to use latest technologies, major standards and instructions and the best human resources in designing, operation and supervision in construction and also protection of it. Also, all authorities and involved of construction and operation of gas industries installation should observe safety criteria, health and environment and aware of them ever. In fact, in designing of these programs, in addition to technical and economical points, environmental characteristics should be considered in order to their construction has minimum damage to environment. On the other hand, common and traditional approaches of pipeline routing are based on using costly and time-consuming methods. In these methods, it is not easily to use all effective parameters in determining optimum way. According to capability of analysis of network spatial information systems in incorporation of spatial data, for using all effective parameters in routing, this environment is used, therefore weighted overlay analysis (Boleyn, index and fuzzy) and shortest path are modeled for finding optimum path of pipeline in GIS environment.
\end{abstract}

\section{Keywords}

Designing Optimum Path, Hierarchical Analysis, Environmental Parameters, Geographical Information System

\section{Introduction}

In the past, alternative is achieved by technical and financial analysis in projects evaluations. Today, projects ${ }^{*}$ Corresponding author.

How to cite this paper: Anvari, H., Feizizadeh, B. and Nejad, R.O. (2016) Optimum Designing of Gas Distribution Networks of Ilam Province by Using GIS Network and Spatial Analysis. Open Journal of Geology, 6, 801-811.

http://dx.doi.org/10.4236/ojg.2016.68062 
showed the stale development of any country. The projects convert organization perspective to reality and manifest the science and technology. One of the most important projects in any country especially in oil rich developing countries is transmission and exportation of nonrenewable energy resources (oil and gas) through pipeline. The economy of these countries is dependent to smooth and accurate operation of them strongly [1]. In fact, pipeline is one of the main ways of transmission of massive volumes of energy. Therefore, companies must design pipeline system with high reliability by selection of optimum path for effective management of pipelines.

However, many cases have reported about destructive effects of projects on environment and individuals in different sections. These effects include removing enormous part of jungles, pastures, agricultural lands and high amount of persons' death. Therefore, to choose optimum path, impact assessment should be performed. For this aim, in addition to technical and financial analysis, environmental effects also should be considered [2].

Since our country is one of the big producers of energy resources (oil and gas) in the world and achieves high amount of its incomes from exportation of gas and oil materials, attention to the transmission ways of these energy resources is very important because using pipeline instead of other transmission ways such as seaways and railway will be more effective and safer. Therefore, choosing proper path for pipeline pass is very important and could have positive effect on state economy and brings more value added. Also we can prevent removing of many jungles, pastures and agricultural lands and minimize the number of people that is affected by destructive effects of pipeline construction [3].

Advanced routing by using GIS:

Routing is one of important and critical branches in gas industry because the cost of pipeline construction is so heavy and any mistake in this filed means wasting national resources, the resources that are protected only when we can find a proper path and consider all economic and environmental factors for it. But common and traditional routing approaches for pipeline did not remove this necessity yet [4] and caused increase of financial and rime costs by choosing long paths and passing illegal areas. In routing of pipelines with common approaches, economic and technical characteristics were considered more and costs or environmental damages that may be incur in construction field and after construction on sensitive ecosystems of path environs are not considered.

But project designing of a pipeline needs incorporation of environmental, engineering-spatial information and information of social-economic costs. The best method to reduce damages, from economic and ecological point of view, is consideration of environmental criteria in zero phase of studies or early routing and avoidance of route passing from ecological sensitive areas. Of course, involving environmental features, in addition to economic and technical features in routing process of pipelines with common approaches, complicate the work process [5]. GIS technology enables the incorporation of high volume information and simplifies understanding more [6].

Oil and gas industry uses GIS technology and science in routing of pipelines as the tool for reducing operational and construction costs. In this process, the factors that should be considered are as follows:

- Shortest path from source to sale market;

- Minimum clearing (removing trees);

- Costs of frontage;

- Minimum pass from river, road and railway;

- Distance from populous centers;

- And other engineering and technical factors.

Much of this information such as land use maps, region soil, fault and many others could be collected by satellite images [6]. Then, images were corrected and become ground reference and in some cases if combining and classifying are necessary, it will be performed. Also, valid and existing maps that are analog become numeral. In next level, by using pairwise comparison and/or based on intended logic according to oil and environment specialists' opinions, existing layers weighted and then overlaid. Finally, based on routing algorithms in related software, analysis and paths with minimum cost, shortest path, minimum environmental damages and maximum safety against natural disasters are [7]. By using GIS, final and general routing of pipelines could be accomplished with higher speed and accuracy. In GIS, algorithms of shortest path are used in vector and network environments. With regards to in this thesis that routing process performed on the ground surface for two points and the subject of optimum routing of pipelines, it is necessary to consider different parameters and criterion and combine data from different resources and finally analyze them. Therefore, network spatial information systems in terms of beneficial equipment and functions such as overlay operation easiness in incorporation of different information layers are suitable for the research purpose [7] [8]. 


\section{Routing in Network Spatial Information System}

Routing algorithm in network environment is similar to operator algorithms in vector environment. To find the route with minimum cost, it is necessary to move on a surface with cumulative cost that this surface shows the cost or resistance against passing from a cell to another cell cumulatively. To move on the surface, we must combine variable descriptions of different cells with each other that is somehow complex. But with map force in network GIS, calculations perform easily themselves. Tomlin has performed lengthy researches about map force [4] [5].

Also, he introduced surface and routing functions by using extension algorithms. His approach was proper for small areas until Eastman introduced the concept of cost surface and implemented in Idrisi software in next years [6] [8]-[10].

Network GIS software, for calculation of shortest path, calculated cost surface with a function to calculate the cost of moving from source to destination and any cell is given the cumulative value; after that reverse action performed [11] [12].

A direction modeling is not simple in raster networks like vector networks but it is possible. Tilt values could be regarded as directions. Moving to neighborhood cells with the same tilt is free but if their tilt is in contrary direction, in this case movement will be prevented [9].

\section{Materials and Approaches}

\subsection{Studied Region and Preparation of Data}

Studied gas distribution region is located in the path between Bahman Abad village to Shoshdar industry zone in the Ilam province, Chovar city, Bahamam Abad village in the west of Iran (Figure 1). The path of pipeline was designed and performed by length of 3100 meters with pipe of 8 inches. It includes several streams and one continual river that river discharge changes with season change.

\subsection{Valuation of Effective Features in Routing of Pipelines}

One of the aspects of the work that its absence in traditional evaluations of infrastructure projects of pipeline



Figure 1. Study area. 
routing may lead to ignore the stability is the kind and the way of valuation and also using underground resources. For undeveloped lands (without construction), no business value is considered for them even if these lands include areas that are sensitive ecologically and consist of herbal and animal kinds which is in extinction.

But established lands gain high value; as a result, the economic resolution for road or pipeline is a path with low value. In other words, irreplaceable resources are chosen and constructed regions which their selection may lead to little damage to future generation in long-term are not considered. Codification of any optimum approach for removing or separating from these barriers and problems and/or changing the land use is so hard without determination of features for correct valuation of resources. The objection of money valuation is that in such cases the resources which are unique and irreplaceable may not be protected.

In other words, this kind of valuation is not enough for assurance of protection of these resources [9]. Therefore, by using approaches, the crossing costs from sensitive environmental regions should be introduced to geographical information system in order to design the path according to them. Of course, quantitative valuation of environmental features is not simple and may lead to fault; because in fact these values are quantitatively. Therefore, environmental qualitative values should be converted to quantitative values by using approaches in order to express the relative weight of them in comparison with economic features and finally prepare the cost maps in next phases according to them.

Several approaches exist for relative weighting and expressing the importance of features rather than each other. These approaches are different in usage easiness, perception amount by decision-makers and theoretical criterion. Decision-maker could choose the beneficial approaches based on previous cases and also availability of related software and the manner of data incorporation with GIS. Pairwise comparison is one of the most valuable and applicable approaches because of strong theoretical base, accuracy, usage easiness, having valuation and validity and correctness [10].

In this approach, at first comparative matrix is formed and features compared dually and their relative weight determined theoretically. The intended relations expressed by qualitative values from 1 to 9 [11]. In this approach, to avoid personal or arbitrary faults in decision-making, gregarious opinions of specialists could be used.

Therefore, in this research after identification of effective features in routing which are shown in Table 1, to determine the relative weight of them and improve the accuracy and avoid personal faults, a questionnaire for using the opinions of specialists related to subject is prepared. The results of these questionnaires are used for dual comparison by using Expert Choice software.

\begin{tabular}{cccc}
\multicolumn{4}{l}{ Table 1. Identification of effective features in routing. } \\
\hline Symbol & Nonstandard & Criterion & Symbol \\
\hline S11 & Residual complexes & & \\
S12 & Continual water regions & & \\
S13 & Seasonal water regions & & C1 \\
S14 & Agricultural lands & Environmental & \\
S15 & Pastures & & \\
S16 & Uncultivated & \\
S17 & Jungle & \\
S21 & Economic resources & \\
S22 & Agricultural lands & \\
S23 & Road & & \\
S24 & River & \\
S25 & Continual river & \\
S26 & Seasonal river & \\
S31 & Residual complexes & \\
S32 & Fault & \\
S33 & Road & \\
S34 & River & \\
S35 & Land type & \\
S36 & Tilt & \\
\hline
\end{tabular}




\subsection{Priority Determination of Main Criterion Based on Purpose}

To perform hierarchical analysis, at first main criterion are compared based on purpose dually. AHP technique is a ranking technique and ranking performed according to dual comparisons in this technique. Dual comparison is so simple and all elements of any cluster should be compared dually. If in a cluster there is (n) elements, $\frac{n(n-1)}{2}$ comparison will be done. Therefore, three dual comparisons are performed from specialists' point of view and by using geometrical average technique, the view of specialists integrated. Dual comparison matrix is shown in Table 2 from integration of specialists' opinions.

The next step is calculation of geometrical average of any lines for determination of criterion weights:

$$
\pi_{1}=\sqrt[3]{1 * 1.280 * 0.883}=1.042
$$

As the same way, geometrical average of other lines is calculated:

$$
\sum_{i=1}^{m} \pi_{i}=1.042+1.003+0.957=3.002
$$

By dividing geometrical average of any line into total of geometrical average of lines, normal weight value is achieved that is called special vector. The summary of results is shown in Table 3.

According to special vector, environmental criterion with normalized weight of 0.347 has maximum priority. Economic criterion with similar weight of 0.336 is in middle priority. Technical criterion with normal weight of 0.317 has minimum priority (Figure 2).

Incompatibility rate of performed comparisons is gained 0.044 that is lower than 0.1 . Therefore, we can trust performed comparisons.

\subsubsection{Comparison and Priority Determination of Nonstandard}

In second step, AHP technique is used in comparison of nonstandard collection related to any criteria dually in own cluster and priorities is settled. The summary of nonstandard dual comparison results of any cluster has shown separately.

Table 2. Dual comparison matrix of main criterion.

\begin{tabular}{cccc}
\hline Technical & Economical & Environmental & Factor \\
\hline 0.883 & 1.280 & 1 & Environmental \\
1.310 & 1 & 0.781 & Economical \\
1 & 0.763 & 1.133 & Technical
\end{tabular}

Table 3. Priority determination of main criterion.

\begin{tabular}{cccccc}
\hline Eigenvector & Mean & Technical & Economical & \multicolumn{2}{c}{ Environmental } \\
\hline 0.347 & 1.042 & 0.883 & 1.280 & 1 & Environmental \\
0.336 & 1.008 & 1.310 & 1 & 0.781 & Economical \\
0.317 & 0.953 & 1 & 0.763 & 1.133 & Technical \\
\hline
\end{tabular}

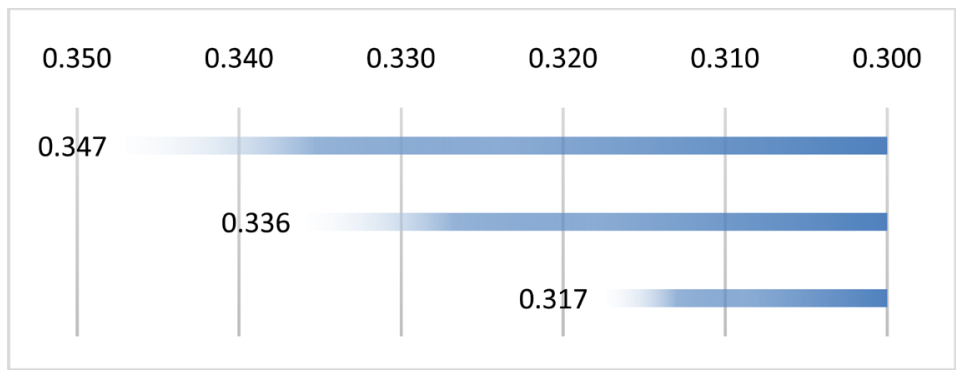

Figure 2. Graphic presentation of main criterion priorities. 


\subsubsection{Priority Determination of Environmental Nonstandard}

Environmental nonstandard are: residual regions, continual water regions, seasonal water regions, agricultural lands, pastures, uncultivated, jungle. Accomplished calculations are shown in Table 4 for determination of environmental nonstandard priorities. Because of seven nonstandard, 21 dual comparisons are done.

According to achieved special vector, the maximum priority is related to the indexes of agricultural lands with the weight of 0.208 . The index of water seasonal regions is in second priority with normal weight of 0.191 . Continual water regions have minimum priority with the weight of 0.178 . Also, compatibility coefficient of performed comparisons is 0.030 . Because this value is lower than 0.1 , so we can trust performed comparisons (Figure 3).

\subsubsection{Determination of Economic Nonstandard Priorities}

Economic nonstandard are: economic resources, agricultural lands, road, river, continual river, seasonal river. Performed calculations presented in Table 5 for determination of economic nonstandard priorities. Because of six nonstandard, 15 dual comparisons are done.

According to achieved special vector, the maximum priority is related to nonstandard of agricultural lands with the weight of 0.200 . Road is second priority with the weight of 0.198 . Also, compatibility coefficient of

Table 4. Dual comparisons of environmental nonstandard.

\begin{tabular}{ccccccccccc}
\hline Special vector & Geometrical average & $S 17$ & $S 16$ & $S 15$ & $S 14$ & $S 13$ & $S 12$ & $S 11$ \\
0.124 & 0.917 & 2.857 & 2.097 & 0.706 & 0.686 & 0.329 & 0.527 & 1 & $S 11$ \\
0.178 & 1.318 & 2.130 & 2.514 & 0.977 & 0.834 & 0.903 & 1 & 1.750 & $S 12$ \\
0.191 & 1.409 & 1.965 & 1.952 & 1.183 & 0.722 & 1 & 1.107 & 3.039 & $S 13$ \\
0.208 & 1.534 & 2.015 & 2.163 & 1.898 & 1 & 1.385 & 1.199 & 1.458 & $S 14$ \\
0.129 & 0.954 & 1.188 & 1.132 & 1 & 0.527 & 0.845 & 0.845 & 1.416 & $S 15$ \\
0.029 & 0.678 & 1.657 & 1 & 0.883 & 0.462 & 0.512 & 0.398 & 0.447 & $S 16$ \\
0.078 & 0.576 & 1 & 0.603 & 0.842 & 0.496 & 0.509 & 0.470 & 0.350 & $S 17$ \\
\hline
\end{tabular}

Table 5. Performed calculations.



Figure 3. Determination of environmental nonstandard priorities. 
performed comparisons is also 0.017. It is lower than 0.1 and as a result we can trust accomplished comparisons (Figure 4).

\subsubsection{Determination of Technical Nonstandard Priorities}

Technical nonstandard are: residual regions, fault, road, river, land type and tilt. Accomplished calculations are presented in Table 6 for determination of economic nonstandard priorities (Table 6).

According to achieved special vector, the maximum priority is related to fault with the weight of 0.258 . Residual regions are in the second priority with the normal weight of 0.232 . Also, compatibility coefficient of accomplished comparisons is 0.052 . Because it is lower than 0.1 , so we can trust accomplished comparisons (Figure 5).

\subsubsection{Final Priority of Indexes with AHP Technique}

In this step, final priority is calculated. Results of research nonstandard and their related weights is formed W2

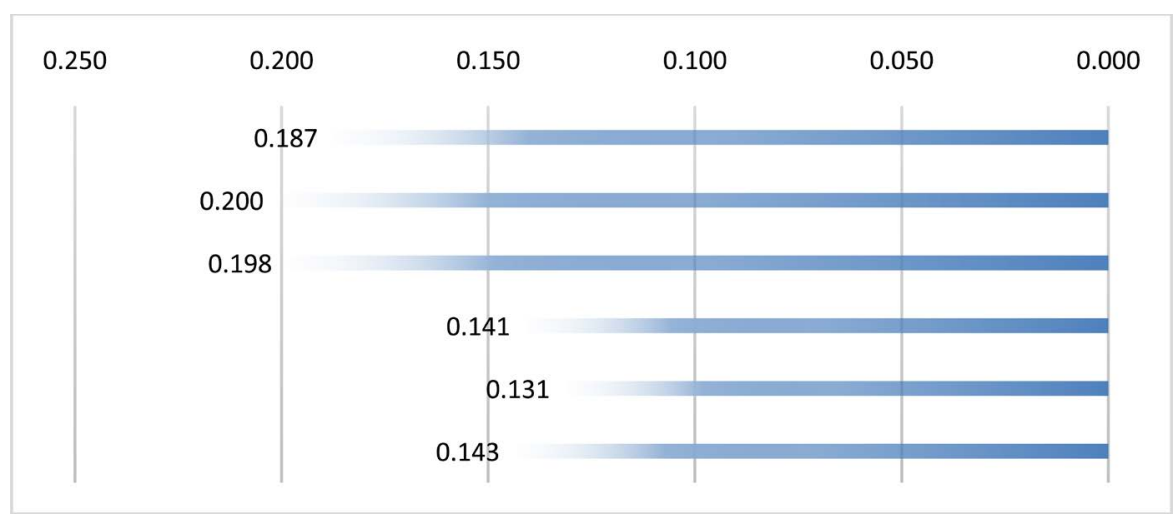

Figure 4. Determination of economic nonstandard priorities.

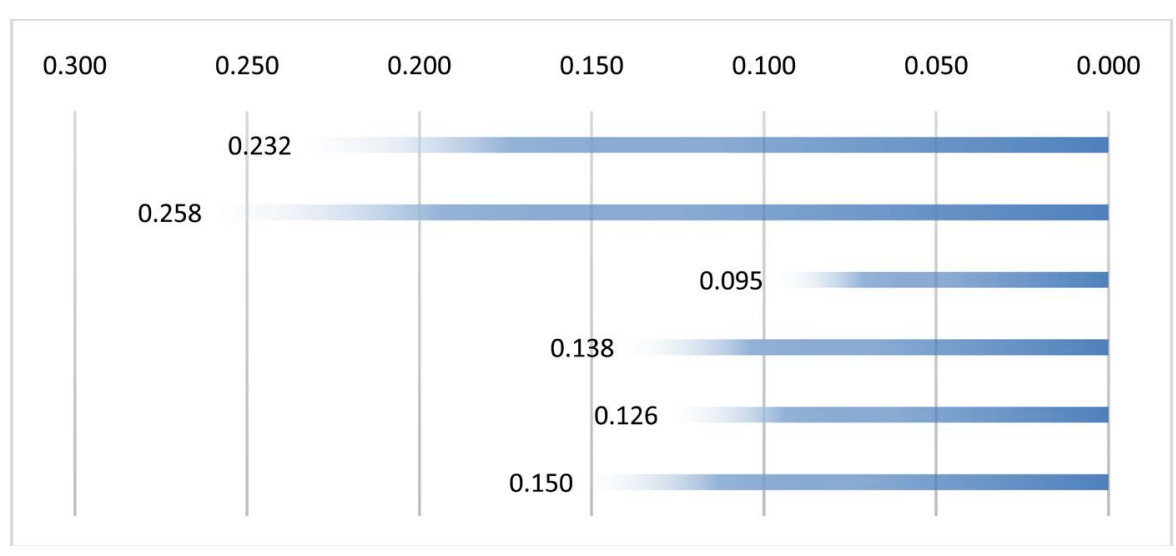

Figure 5. Determination of technical nonstandard priorities.

Table 6. Determination of economic nonstandard priorities.

\begin{tabular}{|c|c|c|c|c|c|c|c|c|}
\hline Special vector & Geometrical average & S36 & S35 & S34 & S33 & S32 & S31 & \\
\hline 0.232 & 1.505 & 1.026 & 2.940 & 1.901 & 2.431 & 0.834 & 1 & S31 \\
\hline 0.258 & 1.675 & 1.609 & 1.632 & 1.719 & 4.073 & 1 & 1.199 & S32 \\
\hline 0.095 & 0.618 & 0.786 & 0.860 & 0.813 & 1 & 0.245 & 0.411 & S33 \\
\hline 0.138 & 0.898 & 1.227 & 1.137 & 1 & 1.230 & 0.582 & 0.526 & S34 \\
\hline 0.126 & 0.816 & 0.728 & 1 & 0.880 & 1.162 & 1.162 & 0.340 & S35 \\
\hline 0.150 & 0.976 & 1 & 1.373 & 0.815 & 1.273 & 0.621 & 0.975 & S36 \\
\hline
\end{tabular}


matrix. To determine final priority of indexes with AHP technique, it is enough to multiply weights of indexes based on any criterion (W2) to the weight of main criterion (W1). With weight of any main criterion (W1) and nonstandard (W2), we can calculate weight of indexes (Table 7).

To perform related calculations, we use Expert Choice software. The results of accomplished calculations and related weights to indexes are presented in Figure 6.

Therefore, fault index (S32) with the weight of 0.0819 has maximum priority. Residual regions index (S31) with the weight of 0.0736 is in second priority. Agricultural lands index (S14) with the weight of 0.0721 is in third priority.

Table 7. Weight of indexes.

\begin{tabular}{|c|c|c|c|c|c|}
\hline Final weight & Primary & Symbol & Nonstandard & Symbol & Criterion \\
\hline 0.0431 & 0.124 & $S 11$ & Residual regions & \multirow{7}{*}{0.347} & \multirow{7}{*}{ Environmental } \\
\hline 0.0619 & 0.178 & $S 12$ & Continual water region & & \\
\hline 0.0662 & 0.191 & $S 13$ & Seasonal water region & & \\
\hline 0.0721 & 0.208 & $S 14$ & Agricultural lands & & \\
\hline 0.0448 & 0.129 & $S 15$ & pastures & & \\
\hline 0.0318 & 0.092 & $S 16$ & uncultivated & & \\
\hline 0.0271 & 0.078 & $S 17$ & jungle & & \\
\hline 0.0628 & 0.187 & $S 21$ & Economic resources & \multirow{6}{*}{0.336} & \multirow{6}{*}{ economic } \\
\hline 0.0672 & 0.200 & $S 22$ & Agricultural lands & & \\
\hline 0.0665 & 0.198 & $S 23$ & road & & \\
\hline 0.0472 & 0.141 & $S 24$ & river & & \\
\hline 0.0440 & 0.131 & $S 25$ & Continual river & & \\
\hline 0.0480 & 0.143 & $S 26$ & Seasonal river & & \\
\hline 0.0736 & 0.232 & S31 & Residual regions & \multirow{6}{*}{0.317} & \multirow{6}{*}{ technical } \\
\hline 0.0819 & 0.258 & S32 & fault & & \\
\hline 0.0302 & 0.095 & S33 & road & & \\
\hline 0.0439 & 0.138 & S34 & river & & \\
\hline 0.0399 & 0.126 & S35 & Land type & & \\
\hline 0.0477 & 0.150 & S36 & tilt & & \\
\hline
\end{tabular}

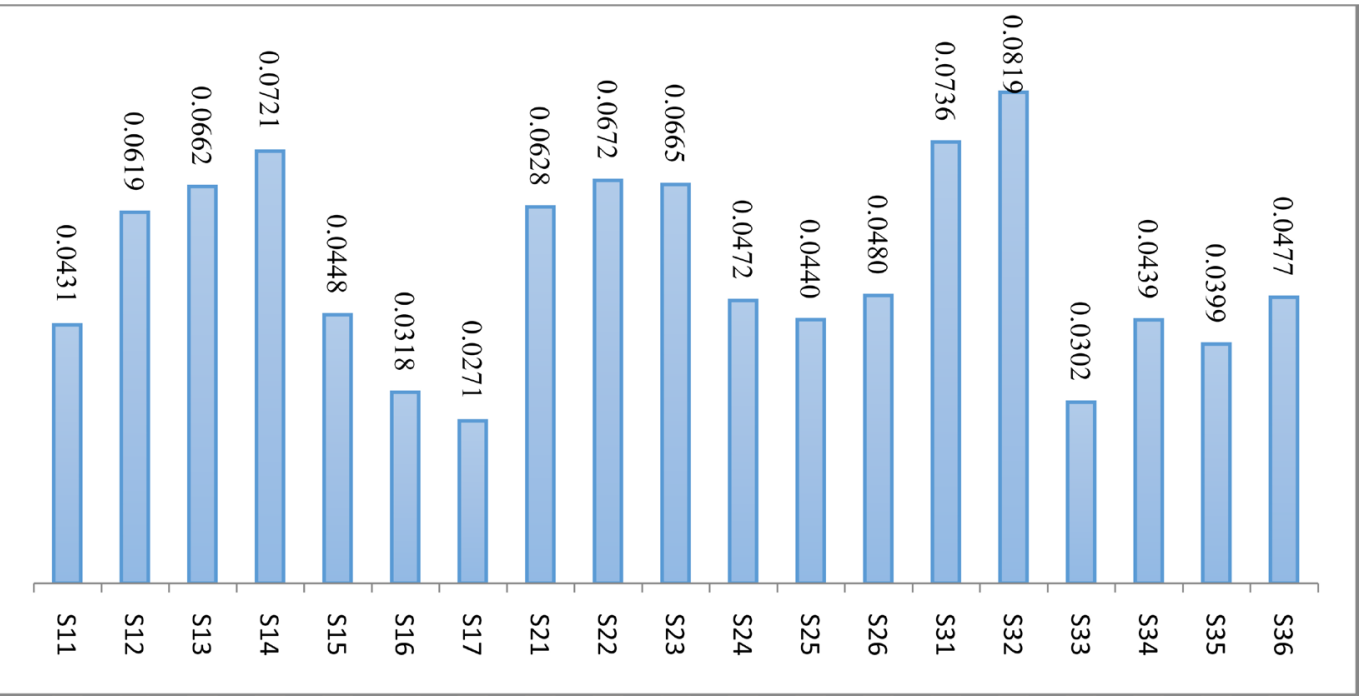

Figure 6. Final priority determination of indexes with AHP technique. 


\subsection{Preparation of Nonstandard Maps}

To prepare criteria maps, we use distance property. The distance which is used in this section is Euclidean distance. In this way, for each pixel, Euclidean distance is achieved from the nearest event related to nonstandard.

Production of derivative maps such as separation from fault is the first step of production of one competency model. Now all pixels in the studied area have a value for each of entering criteria and for any criterion, a nonstandard map is achieved.

In the next step, we should combine a series of derivative data for production of competency map. But their combination is not possible with present manner. For example, the combination of a pixel value that tilt is 8 percent in it with pixel value that its use is 1 or dry jungle are completely incomparable and meaningless. To combine data, it is necessary that all of them weighed. This scale is mutual and determines the competency of any pixel for pipeline passing.

\subsection{Evaluation}

After designing of paths automatically in GIS, each path should be evaluated in terms of observance of environmental features rather than other paths in order to choose the path which inducts lower environmental damage as an optimum path. Selection of optimum path among designed paths regarded as a kind of multi-criteria decision-making.

In this section, suggested optimum path compared with existing pipeline. The length of existing pipeline is about 3100 meters and the length of achieved optimum path which is achieved from GIS spatial and network analysis is about 2949 meters with observance of environmental considerations. In the mentioned figure, it's obvious that existing pipeline passes from regions with higher tilt rather than optimum path.

In mentioned tables, the comparison of paths in terms of passing from different regions is shown. It is observed that in terms of accomplished limitations, suggested path is not passing the tilt higher than 8 percent and in the existing path this case increase the cost of passing.

\section{Discussion}

Oil and gas industry is an important part in national economy of Iran and pipelines and oil and gas transmission lines are vital arteries of energy safety and living in Iran and all around the world. Finally, they have vital role in distribution networks of oil productions. Therefore, to improve the quality of distribution management in designing of pipelines routes, in addition to observance of economic and technical notes we should consider the environmental characteristics which are unique for the region.

As pipelines are widespread in location base, we can use distance measurement technology for identification of environment that is supplement of designing information achievement and also spatial information system technology for modeling and management of data and pipeline. Iran country in terms of extensive network of pipelines, climate and Geomorphology of crisis prone and variability, especially locating in earthquake zone and sensitive ecosystem needs optimum routing of pipelines by using distance technologies and GIS with maintenance of HSE considerations in zero phase of routing studies of pipelines.

The necessity of using GIS systems in designing and implantation and establishment of them become an obvious case today because of extensive volumes of resources and their effects such as environmental effects and high costs which is paid for designing and implantation of pipeline plans. With regards to variability and numerous effective features in routing, using GIS provides beneficial condition for analysis of these data while doing of this work will be difficult and time-consuming with manual approaches. Additionally, in this research after designing of routes automatically by using AHP process, they compared with designed routes manually.

The results showed that these paths are better than paths which are designed manually economically and environmentally. As a result of using network and local analysis of geographical information systems in the present research for studied area, it is resulted to the fact that all information like region tilt, complications in the path, road, river, geological data, fault etc. a weight is achieved by hierarchical approach for all of them. Then, by GIS network and local analysis the achieved weights from mentioned approach assigned to data and combined, finally a general combined map is achieved for region which the limit of studied area could be accessed by achieved map with using GIS network and local analysis and also having first point of route and combined map. 
Then, by first point and combined map and use of tilt map that tilt values could be considered as the flow direction, the map of flow direction could be accessed by incorporating of this combined map and first point and finally with end point, cost map and flow direction map, we can achieve optimum map. Comparison of suggested designed approach an existing pipeline indicated the power of technology of geographical information systems because studied area was small region. In terms of reducing 5 percent of route length, this length is lower than previous accomplished route that generally the route with shortest length is identified as optimum route. But GIS technology questioned this subject.

Because only a path with fewer length is not optimum but a path will be optimum that is designed by considering the defined limitations such as minimum tilt, river, road etc. because in first studies only length is observed and other costs like volumes of earthworks, establishment of service road for operation of route and repairmen, road passing etc. are not considered much. So it is resulted that only path with fewer length is not optimum, but a path is optimum which is designed with fewer length and also observance of all criteria.

And suggested designed path passes from a route which has minimum earthworks and next to Soltan Abad village that it could be devoted to mentioned village and consider for the consumable environs industries. And suggested route in spite of existing pipeline passes from river upstream and it is resistance to increase of river discharge more and more efficient rather than previous path which pipeline passes from downstream of river that is overflow of river because we observe dislocation of pipeline frequently with increase of river discharge.

\section{Suggestions}

At the moment, different companies design the systems for selection of path but these systems are not efficient truly because they lack several problems of designing and we cannot design with them properly. So, by proper and optimum use of distance measurement and designing of a proper GIS system and nourishing of full information to GIS system, we can design suitable package that is applicable in different conditions and situations and can be used in future plans and also for applications of after designing for example different repairmen, operation, protection and analysis.

In designing of path, we can use another effective layers in environmental view like soil corrosion and economic like land ownership. The meaning of these changes is disruption of culture and human connector and life conditions after establishment of pipeline.

It is suggested that in Iranian National Gas company, designing of path in GIS environment performed by expert forces with early simple information like height map and roads, houses and rivers and by determining of spatial location, the suggested path is designed and implemented by simple equipment of mapping like manual GPS in the region and consider the possibility of its applicability. And without expert reference to location, all information of location can be extracted by using height maps and designed with GIS software. Finally, we can observe the difference with previous approaches.

The present research considers the route designing of pipelines between two villages or cities and we can consider the technological abilities of GIS in designing of network lines in the city, introduction of geographical information system in Gas industry and an approach for designing pipelines and nutrition of Gas and integration of local information for future designations. To determine optimum path, we can consider other approaches like artificial intelligence and genetic algorithm.

\section{References}

[1] Berberian, M. and King, G.C.P. (1981) Towards a Paleogeography and Tectonic Evolution of Iran. Canadian Journal of Earth Sciences, 18, 210-265. http://dx.doi.org/10.1139/e81-019

[2] Molinaro, M., Guezou, J.C., Leturmy, P., Eshraghi, S.A. and Frizon de Lamotte, D. (2004) The Origin of Changes in Structural Style across the Bandar Abbas Syntaxis, SE Zagros (Iran). Marine and Petroleum Geology, 21, 735-752. http://dx.doi.org/10.1016/j.marpetgeo.2004.04.001

[3] Sherkati, S. and Letouzey, J. (2004) Variation of Structural Style and Basin Evolution in the Central Zagros (Izeh Zone and Dezful Embayment), Iran. Marine and Petroleum Geology, 21, 535-554. http://dx.doi.org/10.1016/j.marpetgeo.2004.01.007

[4] Walpersdorf, A., Hatzeld, D., Nankali, H., Tavakoli, F., Nilforoushan, F., Tatar, M., Vernant, P., Chery, J. and Masson, F. (2007) Dofferece in GPS Deformation Pattern and Central Zagros (Iran).

[5] Oveisi, B. (2010) Rares and Processes of Active Folding Evidenced by Pleistocene Terraces at the Central Zagros Front 
(Iran).

[6] Bordenave, M.L. (2002) The Middle Cretaceous to Early Miocene Petroleum System in the Zagros Domain of Ira, and Its Prospect Evalution.

[7] Koyi, H. (1988) Experimental Modeling of Role of Gravity and Lateral Shortening in Zagros Mountain Belt.

[8] Lacombe, O., Mouthereau, F., Kargar, S. and Meyer, B. (2006) Late Cenozoic and Modern Stress Fields in the Western Fars (Iran): Implication for the Tectonic and Kinematic Evolution of Central Zagros.

[9] Berberian, M. (1994) Master Blind Thrust Faults Hidden under the Zagros Folds: Active Basement Tectonics and Surface Morphotectonics.

[10] Snyder, D.B. and Barazangi, M. (1986) Deep Crustal Structure and Flexure of the Arabian Plate Beneath the Zagros Collisional Mountain Belt as Inferred from Gravity Observations. Tectonics, 5, 361-373. http://dx.doi.org/10.1029/TC005i003p00361

[11] Talbot, C.J., Medvedev, S., Alavi, M., Shahrivar, H. and Heidari, E. (1997) Salt Extrusion at Kuh-e-Jahani, Iran.

[12] Tatar, M., Hatzfeld, D. and Ghafory-Ashtiany, M. (2003) Tectonics of the Central Zagros (Iran) Deduced from Microearthquake Seismicity.

\section{Submit or recommend next manuscript to SCIRP and we will provide best service for you:}

Accepting pre-submission inquiries through Email, Facebook, LinkedIn, Twitter, etc.

A wide selection of journals (inclusive of 9 subjects, more than 200 journals)

Providing 24-hour high-quality service

User-friendly online submission system

Fair and swift peer-review system

Efficient typesetting and proofreading procedure

Display of the result of downloads and visits, as well as the number of cited articles

Maximum dissemination of your research work

Submit your manuscript at: http://papersubmission.scirp.org/ 